\title{
Como lidar com a morte e o luto? Abordagens psicológicas, teorias, técnicas, instrumentos e/ou intervenções
}

\section{How to deal with death and mourning? Psychological approaches, theories, techniques, instruments and/or interventions}

\author{
Larissa de Araújo Batista Suárez ${ }^{1,2}$, Milena Nunes Alves de Sousa ${ }^{2,3 *}$, Tamyris Luiza de Abreu
} André Luiz Dantas Bezerra ${ }^{2,3}$, Marcus Túlio Caldas ${ }^{1}$

\begin{abstract}
RESUMO
Objetivou-se analisar a abordagem psicológica, teoria, técnica, instrumento e/ou intervenção para auxiliar no lidar com a morte e o luto. Para tanto, o estudo tratou-se de uma revisão integrativa de literatura. $\mathrm{O}$ levantamento bibliográfico foi realizado na internet, na Scientific Electronic Library Online e Literatura Latino-Americana e do Caribe em Ciências da Saúde. Para busca do material foi utilizada a seguinte combinação entre os Descritores em Ciências da Saúde (DeCS): 《< luto OR morte AND psicoterapia 》>. A partir dos critérios de elegibilidade, selecionaram-se para a amostra 15 documentos, os quais foram considerados potenciais. Os resultados evidenciaram que as produções foram publicadas entre 2003 a 2021 , eram estudos de caso e com o perfil da amostra variável. Quanto à abordagem psicológica, destacaram-se a Psicanálise (Sigmund Freud) e a Terapia Cognitivo-Comportamental (Aaron Beck), ambas com 20,0\% $(n=3)$. A teoria base majoritária foi o Protocolo Cognitivo-Comportamental com $26,7 \%(n=4)$ e quanto à técnica, o protocolo de atendimento para luto e as estratégias lúdicas foram as mais aplicadas $(13,3 \% ; n=2$, cada), no mais, as entrevistas foi instrumento mais citado $(33,3 \%$; $n=5)$. Concluiu-se que os profissionais da área de Psicologia têm buscado inúmeras abordagens psicológicas, teorias, técnicas, instrumentos e/ou intervenções para auxiliar os enlutados, portanto, esta revisão é útil para auxiliar na atuação de psicólogos e outros profissionais da área da saúde, a qual exige ações complexas e permanentes, como abordagem holística e integral, escuta qualificada, empatia e atuação interdisciplinar.
\end{abstract}

Palavras-chave: Luto; Atitude Frente a Morte; Psicologia; Práticas Interdisciplinares; Empatia.

\section{ABSTRACT}

The objective of this study was to analyze the psychological approach, theory, technique, instrument and/or intervention to help deal with death and mourning. For this, the study was an integrative literature review. The bibliographic survey was conducted on the Internet, at the Scientific Electronic Library Online and Latin American and Caribbean Literature in Health Sciences. To search for the material, the following combination was used between the Descriptors in Health Sciences (DeCS): < < or death OR psychotherapy >>. Based on the eligibility criteria, 15 documents were selected for the sample, which were considered potential. The results showed that the productions were published between 2003 and 2021, were case studies and with the variable sample profile. As for the psychological approach, psychoanalysis (Sigmund Freud)

\footnotetext{
${ }^{1}$ Universidade Católica do Pernambuco (UNICAP), Recife, Pernambuco, Brasil.

${ }^{2}$ Faculdade São Francisco da Paraíba (FASP), Cajazeiras, Paraíba, Brasil.

${ }^{3}$ Centro Universitário de Patos (UNIFIP), Patos, , Paraíba, Brasil.

* E-mail: milenanunes@ fiponline.edu.br

${ }^{4}$ Prefeitura Municipal de Cajazeiras, Cajazeiras, Paraíba, Brasil.
} 
and Cognitive Behavioral Therapy (Aaron Beck), both with $20.0 \%$ ( $n=3)$, stood out. The majority base theory was the Cognitive-Behavioral Protocol with $26.7 \%(n=4)$ and regarding the technique, the care protocol for mourning and the playful strategies were the most applied (13.3\%; $n=2$, each), in addition, the interviews were the most cited instrument $(33.3 \%$; $=5)$. It was concluded that psychology professionals have sought numerous psychological approaches, theories, techniques, instruments and/or interventions to assist the bereaved, therefore, this review is useful to assist in the performance of psychologists and other health professionals, which requires complex and permanent actions, such as holistic and comprehensive approach, qualified listening, empathy and interdisciplinary action.

Keywords: Bereavement; Attitude to Death; Psychology; Interdisciplinary Placement; Empathy.

\section{INTRODUÇÃO}

A morte é um acontecimento sempre inesperado e que se faz presente no cotidiano de forma inevitável, além disso, acarretada problemas orgânicos e psicológicos (AQUINO; VASCONCELOS; BRAGA, 2014; COSTA; NJAINE; SOUZA, 2020; SUÁREZ; SOUSA; CALDAS, 2020). Vista como um tabu, muitos mistérios e crenças a cercam, e os indivíduos, habitualmente, se encontram despreparadas para lidar com a finitude da vida humana (BASSO; WAINER, 2011).

A perda de um familiar, por exemplo, é um evento de grande potencial traumático, capaz de desencadear sofrimento intenso e importante impacto à saúde física e mental, problemas financeiros e enfraquecimento dos laços sociais (COSTA; NJAINE; SOUZA, 2020; SUÁREZ; SOUSA; CALDAS, 2020). E o luto é vivenciado como um fato "intersubjetivo e como experiência de perda de um mundo partilhado que se rompe com a morte. Ao se perder um ente querido, perdem-se também uma perspectiva e uma possibilidade existencial, cabendo ao enlutado a ressignificação de seu existir” (MICHEL; FREITAS, 2019, p. 1).

Entretanto, reconhece-se que o processo de luto, em qualquer circunstância, causa uma demanda psicológica, uma vez que é inerente ao ser humano o enfrentamento e as dificuldades com as perdas, principalmente de pessoas significativas (SILVA; CARNEIRO; ZANDONADI, 2017). De acordo com os autores, a perda é considerada uma das experiências mais dolorosas para o indivíduo, repercutindo na necessidade de atuação dos profissionais capacitados para o desenvolvimento da prática de ressignificar o morrer.

Importante considerar que a morte tem significados diferentes para cada pessoa, pois é algo ameaçador, um assunto ainda longe das pautas de conversações entre aqueles que respiram e aspiram à vida (SILVA; CARNEIRO; ZANDONADI, 2017; SUÁREZ; SOUSA; CALDAS, 2020). Destarte, muitos profissionais da saúde sentem-se despreparados para o "estar ao lado", devido não suportarem sua impotência diante desta hora inevitável (MOCELIN et al., 2014; 
FARIA; FIGUEREIDO, 2017; LIMA; ANDRADE, 2017; FERREIRA; NASCIMENTO; SÁ, 2018; MENDES et al., 2020).

Tais discussões e intervenções são cada vez mais necessárias, já que compreender a morte e o morrer contribui para o desenvolvimento pessoal holístico (KOVÁCS, 2005) Mediante o alcance de sentido poder-se-á viver de modo mais resiliente com a certeza da morte e a busca incessante da valorização da vida.

Ante as ponderações, objetiva-se analisar a abordagem psicológica, teoria, técnica, instrumento e/ou intervenção para auxiliar no lidar com a morte e o luto. Portanto, espera-se contribuir para o acesso, reflexão e ação diante do objeto de estudos e, assim, desenvolver práticas educacionais que favoreçam o processo de educação para a morte e a importância do debate.

\section{METODOLOGIA}

O presente estudo tratou-se de uma revisão integrativa de literatura (RIL), com abordagem qualitativa, a qual deve ser realizada em seis fases (SOUSA, 2016). Este método de revisão inclui a análise de pesquisas relevantes que dão suporte para a tomada de decisão e a melhoria da prática clínica, dessa forma possibilitando a síntese do estado do conhecimento de um determinado assunto, além de apontar lacunas do conhecimento que precisam ser preenchidas com a realização de novos estudos. Este método de pesquisa permite a síntese de múltiplos estudos publicados e possibilita conclusões gerais a respeito de uma particular área de estudo (HERMONT et al., 2021).

Preliminarmente, partiu-se da seguinte questão de pesquisa: qual a abordagem psicológica, teoria, técnica, instrumento e/ou intervenção para auxiliar no lidar com a morte e o luto? O levantamento bibliográfico foi realizado no período de setembro a outubro de 2021, por meio da internet, no endereço eletrônico da plataforma da Scientific Electronic Library Online (SciELO) e Literatura Latino-Americana e do Caribe em Ciências da Saúde (LILACS).

Para busca do material foi utilizada a seguinte combinação entre os Descritores em Ciências da Saúde (DeCS): << luto OR morte AND psicoterapia 〉>. Utilizaram-se como critérios de inclusão os artigos em português, independentemente do método de pesquisa utilizado e publicados nos últimos 10 anos. Excluíram-se os documentos que não correspondiam ao objeto de estudo, textos incompletos ou indisponíveis na íntegra online e as repetições, em que se manteve apenas uma vez. 
Figura 1 - Fluxograma referente ao processo de identificação dos artigos.

Qual a abordagem psicológica, teoria, técnica, instrumento e/ou intervenção para auxiliar no lidar com a morte e o luto?

Uso da combinação entre os DeCS $<<$ luto OR morte $A N D$ psicoterapia $>>$

\begin{tabular}{|c|c|}
\hline $\begin{array}{l}\text { SciELO } \\
\text { (10 artigos) }\end{array}$ & $\begin{array}{l}\text { LILACS } \\
\text { (79 artigos) }\end{array}$ \\
\hline \multicolumn{2}{|l|}{$\Downarrow$} \\
\hline $\begin{array}{l}\text { Total de artigos identificados nas duas bases de dados (89 } \\
\text { artigos) }\end{array}$ & $\Rightarrow \begin{array}{c}\text { - Artigos em português } \\
\text { - Publicados nos últimos } 10 \\
\text { anos }\end{array}$ \\
\hline $\begin{array}{l}\text { Aplicação dos critérios de inclusão e exclusão } \\
\text { (30 artigos) }\end{array}$ & $\begin{array}{l}\text { - Não correspondiam ao } \\
\text { objeto de estudo } \\
\text { - Textos incompletos ou } \\
\text { indisponíveis na íntegra } \\
\text { - As repetições }\end{array}$ \\
\hline \multicolumn{2}{|r|}{ 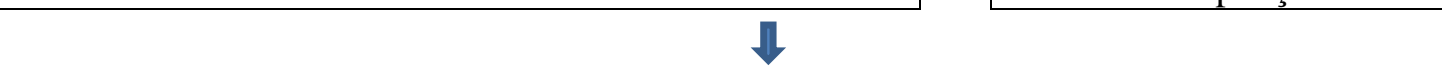 } \\
\hline \multicolumn{2}{|l|}{ Amostra final: 15 publicações } \\
\hline
\end{tabular}

Fonte: Dados de pesquisa em base de dados, 2021.

Após a seleção dos artigos para compor o estudo, foi realizada uma leitura criteriosa das publicações com o propósito de organizar e sintetizar as informações para responder aos objetivos da revisão. Neste processo, foram selecionadas as seguintes variáveis: autor, ano, plataforma de busca, periódico, abordagem psicológica, teoria, técnica, instrumento e/ou intervenção para lidar com a morte e o luto.

Por último, efetivou-se a interpretação dos dados obtidos, a avaliação e a apresentação dos resultados. Nesta fase, as informações presentes nos artigos selecionados foram organizadas de forma descritiva, com o objetivo de facilitar a realização do estudo e a compreensão dos dados.

\section{RESULTADOS}

De acordo com o Quadro 1, o qual contempla a caracterização geral dos artigos selecionados para compor a RIL $(n=15)$, verificou-se que as produções foram publicadas entre 2003 a 2021, em que o ano de 2011 destacou-se entre os demais (20,0\%; $n=3)$, a maioria estava disponível exclusivamente na LILACS $(66,7 \% ; n=10)$ e eram estudos de caso $(53,3 \% ; n=8)$ e qualitativos (46,7\%; n=7), publicados em 100\% de revistas da área de Psicologia e com uma amostra variável.

Quadro 1 - Caracterização geral dos artigos selecionados para compor a RIL. 


\begin{tabular}{|c|c|c|c|c|}
\hline $\begin{array}{c}\text { Autores/ } \\
\text { Ano }\end{array}$ & $\begin{array}{c}\text { Plataforma de } \\
\text { busca }\end{array}$ & Periódico & Tipo de estudo & Amostra \\
\hline $\begin{array}{l}\text { Aguirre e Arruda } \\
\text { (2006) }\end{array}$ & SCIELO & $\begin{array}{ll}\text { Estudos } & \text { de } \\
\text { Psicologia } & \\
\text { (Campinas) } & \end{array}$ & $\begin{array}{l}\text { Estudo de caso/ } \\
\text { qualitativo }\end{array}$ & $\begin{array}{l}\text { Criança } \quad \text { com } \\
\text { Síndrome da } \\
\text { Imunodeficiência } \\
\text { Adquirida }\end{array}$ \\
\hline Corrêa (2012) & LILACS & $\begin{array}{l}\text { Psicologia: teoria e } \\
\text { prática }\end{array}$ & $\begin{array}{l}\text { Estudo de caso/ } \\
\text { qualitativo }\end{array}$ & $\begin{array}{l}\text { Mulher que perdeu o } \\
\text { pai }\end{array}$ \\
\hline $\begin{array}{l}\text { Costa, Mota e } \\
\text { Milheiro (2013) }\end{array}$ & LILACS & Psicologia Clínica & Estudo de caso & $\begin{array}{l}\text { Mulher com } \\
\text { depressão } \\
\text { decorrente de perdas }\end{array}$ \\
\hline $\begin{array}{ll}\text { Cravinho } & \text { e } \\
\text { Cunha (2015) } & \end{array}$ & LILACS & $\begin{array}{l}\text { Estudos de } \\
\text { Psicologia } \\
\text { (Campinas) }\end{array}$ & $\begin{array}{l}\text { Pesquisa de campo/ } \\
\text { quantitativa }\end{array}$ & $\begin{array}{l}36 \text { profissionais de } \\
\text { enfermagem }\end{array}$ \\
\hline Dantas (2016) & LILACS & $\begin{array}{l}\text { Psicologia } \\
\text { Argumento }\end{array}$ & Bibliográfico & $\begin{array}{lr}\text { Família } & \text { de } \\
\text { Indivíduos com } \\
\text { Amiotrofia } \\
\text { Muscular Espinal } \\
\end{array}$ \\
\hline Elias (2003) & SCIELO & $\begin{array}{l}\text { Psicologia: } \\
\text { Ciência } \\
\text { Profissão }\end{array}$ & $\begin{array}{l}\text { Pesquisa de campo/ } \\
\text { qualitativa }\end{array}$ & $\begin{array}{lr}\text { crianças } & \text { e } 3 \\
\text { adolescentes } & \text { com } \\
\text { câncer } & \end{array}$ \\
\hline $\begin{array}{ll}\text { Fukumitsu } & \text { e } \\
\text { Kovács (2016) }\end{array}$ & LILACS & Psico & Qualitativo & $\begin{array}{l}9 \text { filhos de pessoas } \\
\text { que consumaram o } \\
\text { suicídio }\end{array}$ \\
\hline $\begin{array}{l}\text { Michel e Freitas } \\
\text { (2021) }\end{array}$ & $\begin{array}{l}\text { SCIELO/ } \\
\text { LILACS }\end{array}$ & $\begin{array}{l}\text { Psicologia: } \\
\text { Ciência } \\
\text { Profissão }\end{array}$ & Qualitativo & 4 mães \\
\hline $\begin{array}{l}\text { Moreira e } \\
\text { Holanda (2010) }\end{array}$ & SCIELO & Psico-USF & Bibliográfico & Não se aplica \\
\hline Oishi (2014) & $\begin{array}{l}\text { SCIELO/ } \\
\text { LILACS }\end{array}$ & $\begin{array}{l}\text { Psicologia: teoria e } \\
\text { pesquisa }\end{array}$ & Qualitativo & $\begin{array}{l}\text { Mulher que perdeu } \\
\text { filho }\end{array}$ \\
\hline $\begin{array}{l}\text { Schmidt, Gabarra } \\
\text { e Gonçalves } \\
\text { (2011) }\end{array}$ & LILACS & $\begin{array}{l}\text { Paidéia (Ribeirão } \\
\text { Preto) }\end{array}$ & $\begin{array}{l}\text { Relato } \\
\text { experiência/ } \\
\text { estudo de caso }\end{array}$ & $\begin{array}{l}\text { Homem em estado } \\
\text { terminal e familiares }\end{array}$ \\
\hline $\begin{array}{l}\text { Silva e Nardi } \\
\text { (2011a) }\end{array}$ & LILACS & $\begin{array}{l}\text { Archives of } \\
\text { Clinical Psychiatry } \\
\text { (São Paulo) }\end{array}$ & Estudo de caso & $\begin{array}{l}\text { Mulher com perda } \\
\text { gestacional }\end{array}$ \\
\hline $\begin{array}{l}\text { Silva e Nardi } \\
(2011 b)\end{array}$ & LILACS & $\begin{array}{l}\text { Archives of } \\
\text { Clinical Psychiatry } \\
\text { (São Paulo) }\end{array}$ & Estudo de caso & Viúva de 29 anos \\
\hline Strauch (2017) & LILACS & $\begin{array}{ll}\text { Rev. } & \text { bras. } \\
\text { psicodrama } & \end{array}$ & $\begin{array}{l}\text { Relato de caso e } \\
\text { Relato grupal }\end{array}$ & $\begin{array}{l}\text { - Mulher de } 22 \text { anos; } \\
-26 \text { pessoas }(21 \\
\text { mulheres e } 5 \\
\text { homens, entre } 25 \text { e } \\
55 \text { anos }\end{array}$ \\
\hline $\begin{array}{l}\text { Tsutsumi et al. } \\
\text { (2017) }\end{array}$ & LILACS & $\begin{array}{l}\text { Revista Brasileira } \\
\text { de Psicoterapia }\end{array}$ & Relato de caso & Menino de 6 anos \\
\hline
\end{tabular}

Fonte: Dados de pesquisa em base de dados, 2021.

No Quadro 2, apresenta-se a categorização dos estudos quanto a abordagem psicológica, teoria, técnica, instrumento e/ou intervenção dos estudos selecionados nesta RIL. Portanto, quanto à abordagem psicológica, destacaram-se a Psicanálise (Sigmund Freud) e a Terapia CognitivoComportamental (Aaron Beck), ambas com 20,0\% (n=3). A teoria base majoritária foi o Protocolo Cognitivo-Comportamental com $26,7 \%$ ( $\mathrm{n}=4$ ). 
Ainda, quanto às técnicas e aos instrumentos e/ou intervenções, adaptaram-se a amostra e foram bem variadas. Na técnica, o protocolo de atendimento para luto e as estratégias lúdicas foram as mais aplicadas $(13,3 \% ; n=2$, cada) e a respeito dos instrumentos e/ou intervenções, as entrevistas foram as mais citadas $(33,3 \% ; \mathrm{n}=5)$.

Quadro 2 - Categorização dos estudos quanto a abordagem psicológica, teoria, técnica, instrumento e/ou intervenção conforme estudos selecionados na RIL.

\begin{tabular}{|c|c|c|c|c|}
\hline $\begin{array}{c}\text { Autores/ } \\
\text { Ano }\end{array}$ & $\begin{array}{c}\begin{array}{c}\text { Abordagem } \\
\text { psicológica }\end{array} \\
\end{array}$ & Teoria base & Técnica & Instrumento e/ou Intervenção \\
\hline $\begin{array}{l}\text { Aguirre e } \\
\text { Arruda } \\
\text { (2006) }\end{array}$ & $\begin{array}{l}\text { Psicanálise } \\
\text { (Melanie Klein); }\end{array}$ & $\begin{array}{l}\text { Psicoterapia lúdica } \\
\text { psicodinâmica; }\end{array}$ & $\begin{array}{l}\text { Estratégias } \\
\text { lúdicas - Técnica } \\
\text { do brinquedo }\end{array}$ & $\begin{array}{l}\text { Entrevistas e a hora de jogo } \\
\text { diagnóstica. }\end{array}$ \\
\hline $\begin{array}{l}\text { Corrêa } \\
(2012)\end{array}$ & $\begin{array}{l}\text { Logoterapia e } \\
\text { Análise } \\
\text { Existencial } \\
\text { (Viktor Frankl) }\end{array}$ & $\begin{array}{l}\text { Sentido da vida; } \\
\text { Autotranscedência; } \\
\text { Valores de atitude. }\end{array}$ & Baú de vivências & $\begin{array}{l}\text { Narrativa de experiências e } \\
\text { valores criativos. }\end{array}$ \\
\hline $\begin{array}{l}\text { Costa, } \\
\text { Mota e } \\
\text { Milheiro } \\
(2013)\end{array}$ & $\begin{array}{l}\text { Psicanálise } \\
\text { (Sigmund Freud) }\end{array}$ & Psicodinâmica; & $\begin{array}{l}\text { Análise da } \\
\text { história clínica } \\
\text { da paciente }\end{array}$ & $\begin{array}{l}\text { Teste de personalidade de } \\
\text { Rorschach (sistema } \\
\text { compreensivo de Nina Raus, } \\
\text { Rorschach, 1953) } \\
\text { SCL-90 (Symptom Checklist, } \\
\text { Derogatis, 1994) } \\
\text { Inventário Clínico de Auto } \\
\text { Conceito (Serra, 1986) } \\
\text { Escala de Depressão de Auto } \\
\text { Avaliação de Zung (Zung, } \\
\text { 1965). }\end{array}$ \\
\hline $\begin{array}{l}\text { Cravinho } \\
\text { e Cunha } \\
(2015)\end{array}$ & $\begin{array}{l}\text { Behaviorismo } \\
\text { (Skinner } \\
\text { colaboradores) }\end{array}$ & $\begin{array}{l}\text { Protocolo } \\
\text { Cognitivo } \\
\text { Comportamental }\end{array}$ & $\begin{array}{l}\text { Abordagem } \\
\text { Disposicional e } \\
\text { a Teoria } \\
\text { Motivacional do } \\
\text { Coping }\end{array}$ & $\begin{array}{l}\text { Inventário COPE (Carver et al., } \\
\text { 1989) } \\
\text { Roteiro de Entrevista Coping } \\
\text { Motivacional: uma adaptação da } \\
\text { Motivational Theory of Coping } \\
\text { Scale-12 (MCT-12) de Lees } \\
(2007) \text {. }\end{array}$ \\
\hline $\begin{array}{l}\text { Dantas } \\
(2016)\end{array}$ & $\begin{array}{l}\text { Psicanálise (John } \\
\text { Bowlby) }\end{array}$ & Teoria do Apego & $\begin{array}{l}\text { Rompimento do } \\
\text { vínculo }\end{array}$ & $\begin{array}{l}\text { Prática equoterapêutica ou } \\
\text { equoterapia. }\end{array}$ \\
\hline $\begin{array}{l}\text { Elias } \\
(2003)\end{array}$ & $\begin{array}{l}\text { Psicanálise } \\
\text { (Sigmund Freud) }\end{array}$ & Psicoterapia Breve & $\begin{array}{l}\text { Técnicas de } \\
\text { relaxamento } \\
\text { mental }\end{array}$ & $\begin{array}{l}\text { Visualização de imagens } \\
\text { mentais com os elementos que } \\
\text { descrevem a natureza da } \\
\text { espiritualidade. }\end{array}$ \\
\hline $\begin{array}{l}\text { Fukumits } \\
\text { u e } \\
\text { Kovács } \\
(2016)\end{array}$ & $\begin{array}{l}\text { Gestalt } \quad \text { (Fritz } \\
\text { Perls) }\end{array}$ & Gestalt-terapia & Posvenção & $\begin{array}{ll}\text { Método } & \text { fenomenológico } \\
\text { proposto por } & \text { Clark Moustakas } \\
\text { (1994); } & \\
\text { Entrevista (análises dos } \\
\text { depoimentos). }\end{array}$ \\
\hline $\begin{array}{l}\text { Michel e } \\
\text { Freitas } \\
(2021)\end{array}$ & Fenomenologia & $\begin{array}{lr}\text { Método empírico- } \\
\text { enomenológico de } \\
\text { investigação em } \\
\text { psicologia } \\
\text { Amedeo Giorgi }\end{array}$ & $\begin{array}{l}\text { Pergunta } \\
\text { disparadora }\end{array}$ & $\begin{array}{l}\text { Eixos temáticos, a saber: relação } \\
\text { terapeuta-paciente, } \\
\text { possibilidades expressivas que } \\
\text { emergem da relação } \\
\text { psicoterápica e ressignificação. }\end{array}$ \\
\hline $\begin{array}{l}\text { Moreira e } \\
\text { Holanda } \\
(2010)\end{array}$ & $\begin{array}{l}\text { Logoterapia e } \\
\text { Análise } \\
\text { Existencial } \\
\text { (Viktor Frankl) }\end{array}$ & $\begin{array}{l}\text { Sentido da vida; } \\
\text { Dimensões } \\
\text { espirituais }\end{array}$ & $\begin{array}{l}\text { Não } \\
\text { especificado }\end{array}$ & Não especificado. \\
\hline
\end{tabular}




\begin{tabular}{|c|c|c|c|c|}
\hline $\begin{array}{l}\text { Oishi } \\
(2014)\end{array}$ & $\begin{array}{l}\text { Psicanálise } \\
\text { (Sigmund Freud) }\end{array}$ & Psicoterapia Breve & $\begin{array}{l}\text { Psicoterapia } \\
\text { individual }\end{array}$ & $\begin{array}{l}\text { Acolhimento; } \\
\text { Facilitação da expressão dos } \\
\text { sentimentos relativos à perda. }\end{array}$ \\
\hline $\begin{array}{l}\text { Schmidt, } \\
\text { Gabarra e } \\
\text { Gonçalve } \\
\text { s (2011) }\end{array}$ & $\begin{array}{l}\text { Sistêmica } \\
\text { Familiar }\end{array}$ & $\begin{array}{l}\text { Psicoterapia } \\
\text { Hospitalar Breve }\end{array}$ & $\begin{array}{l}\text { Fortalecimento } \\
\text { de vínculos }\end{array}$ & $\begin{array}{l}\text { Genograma familiar; } \\
\text { Ritual de despedida no } \\
\text { enfrentamento e na aceitação da } \\
\text { morte. }\end{array}$ \\
\hline $\begin{array}{l}\text { Silva e } \\
\text { Nardi } \\
(2011 a)\end{array}$ & $\begin{array}{l}\text { Cognitivo- } \\
\text { Comportamental } \\
\text { (Aaron Beck) }\end{array}$ & $\begin{array}{l}\text { Protocolo } \\
\text { Cognitivo } \\
\text { Comportamental }\end{array}$ & $\begin{array}{l}\text { Psicoeducação; } \\
\text { Protocolo } \\
\text { terapêutico para } \\
\text { luto }\end{array}$ & $\begin{array}{l}\text { Entrevista; } \\
\text { Inventário Beck de Depressão; } \\
\text { Inventário Beck de Ansiedade; } \\
\text { Escala Beck de Desesperança; } \\
\text { Questionário de Saúde Geral de } \\
\text { Goldberg. }\end{array}$ \\
\hline $\begin{array}{l}\text { Silva e } \\
\text { Nardi } \\
(2011 b)\end{array}$ & $\begin{array}{l}\text { Cognitivo- } \\
\text { Comportamental } \\
\text { (Aaron Beck) }\end{array}$ & $\begin{array}{l}\text { Protocolo } \\
\text { Cognitivo } \\
\text { Comportamental }\end{array}$ & $\begin{array}{l}\text { Protocolo de } \\
\text { atendimento } \\
\text { para luto }\end{array}$ & $\begin{array}{l}\text { Entrevista; } \\
\text { Inventário Beck de Depressão; } \\
\text { Inventário Beck de Ansiedade; } \\
\text { Escala Beck de Desesperança; } \\
\text { Inventário de Sintomas de Stress } \\
\text { de Lipp; e } \\
\text { Questionário de Saúde Geral. }\end{array}$ \\
\hline $\begin{array}{l}\text { Strauch } \\
(2017)\end{array}$ & $\begin{array}{l}\text { Psicodrama } \\
\text { (Jacob Levy } \\
\text { Moreno) }\end{array}$ & $\begin{array}{l}\text { Psicoterapia } \\
\text { Individual; } \\
\text { Vivência aberta em } \\
\text { Grupo }\end{array}$ & $\begin{array}{l}\text { Ressignificação } \\
\text { do luto, nas } \\
\text { modalidades } \\
\text { individual e } \\
\text { grupal }\end{array}$ & $\begin{array}{l}\text { Método sociopsicodramático: } \\
\text { 1) Aquecimento; } \\
\text { 2) Dramatização; } \\
\text { 3) Compartilhamento de } \\
\text { sentimentos, avaliação e } \\
\text { formulação de esclarecimentos. }\end{array}$ \\
\hline $\begin{array}{l}\text { Tsutsumi } \\
\text { et al. } \\
(2017)\end{array}$ & $\begin{array}{l}\text { Cognitivo- } \\
\text { Comportamental } \\
\text { (Aaron Beck) }\end{array}$ & $\begin{array}{l}\text { Terapia Analítico- } \\
\text { Comportamental } \\
\text { Infantil }\end{array}$ & $\begin{array}{l}\text { Estratégias } \\
\text { lúdicas: jogos, } \\
\text { brincadeiras e } \\
\text { fantasia }\end{array}$ & Jogo dos Sentimentos. \\
\hline
\end{tabular}

Fonte: Dados de pesquisa em base de dados, 2021.

\section{DISCUSSÃO}

O modo de lidar com a morte depende de capacidades individuais do enlutado, ou seja, dos ajustamentos internos, das inter-relações e adaptações criativas realizadas mediante interação com o ambiente (FUKUMITSU; KOVÁCS, 2016). Afinal, conforme os autores, é um momento marcado pela "ausência presente e presença ausente", ou seja, significa a falta que se torna presente devido a morte de uma pessoa querida.

Atenção especial deve ser dada pelos profissionais da saúde para aqueles indivíduos em luto por morte autoinfligida, sendo importante expandir as reflexões sobre recursos e estratégias para lidar com o luto e a morte (FUKUMITSU; KOVÁCS, 2016). Diante disto, os psicólogos vêm buscando incontáveis abordagens psicológicas, teorias, técnicas, instrumentos e/ou intervenções para auxiliar os enlutados, como foi possível visualizar nesta RIL e com resultados satisfatórios.

Aguirre e Arruda (2006), a partir de um estudo de caso de uma criança com Síndrome da Imunodeficiência Adquirida (Acquired Immunodeficiency Syndrome - AIDS) e com pais falecidos em decorrência da enfermidade, a mesma expressou-se por desenhos, em que a negação 
foi o mecanismo de defesa inicial, mas outras defesas e maneiras de expressão surgiram com a ludoterapia, tais como a raiva e revolta, pois a criança sentia-se culpada pela doença, pela perda dos pais, manifestando sentimentos de desamparo e abandono. Com a intervenção terapêutica, o menino foi modicando seu modo de expressar-se e de sentir, melhorando a forma de lidar com seus conflitos, tornando-se mais espontâneo e alegre.

Corrêa (2012), em outro estudo de caso, mas sobre as vivências do luto de uma paciente que perdeu o pai constatou, a partir de narrativa de experiências e valores criativos, em que foi realizado um processo psicoterapêutico (Logoterapia), propiciou a descoberta eficaz do sentido para o luto. A mulher foi convencida que, mesmo sem a presença física do pai, era possível continuar unida pelas vivencias em vida com ele, em que vínculo amoroso transcende a temporalidade da vida e reafirma os valores da ligação entre ambos. Portanto, com a intervenção, a mesma foi proativa e seu luto foi modificado pela descoberta de sentido.

Para Frankl (2013) e Suárez, Caldas e Sousa (2018) o sentido de vida é encontrado pelo ser humano através da sua compreensão dos valores existenciais, os quais permitem atingir a autotranscendência através da liberdade de se posicionar diante das situações, tornando-o capaz de realizar projetos dotados significados.

Moreira e Holanda (2010), a partir de estudo de revisão bibliográfica, afirma que a Logoterapia, ao resgatar e apreciar o conceito de homo religiosus, possibilita superar a existência humana para além da natureza do homo patiens, concebendo a capacidade de resiliência como um determinante para identificar e enfrentar o sofrimento próprio da vida humana e participante do seu significado.

Costa, Mota e Milheiro (2013) descreve a experiência de mulher com depressão e sentimentos angustiantes decorrentes de perdas. A avaliação, em que foram usados vários instrumentos, revelou sentimentos latentes de culpa perante os conflitos internos. Através da Psicanálise (Sigmund Freud), em que o processo de acompanhamento psicológico, foi concebido pelo modelo psicodinâmico, buscou-se facilitar a vivência do luto, com a finalidade de aceitação e elaboração da perda. A estratégia intervencionista possibilitou redução da ansiedade, além de ampliar a capacidade de pensar sobre os seus sentimentos e emoções, facilitando a lida com os conflitos internos atenuando os pensamentos ruminativos em torno do falecimento do pai e da dependência materna.

Cravinho e Cunha (2015) realizaram uma pesquisa de campo/quantitativa em que consideraram duas abordagens - a Disposicional e a Teoria Motivacional do Coping. Participaram 36 profissionais de enfermagem de dois hospitais públicos, os quais lidavam com a morte fetal utilizando essencialmente como principais estratégicas de enfrentamento: Negociação, Busca de Informação, Autoconfiança e Busca de Suporte (Entrevista); e pela Religiosidade, Reinterpretação positiva e Planejamento. Os autores apontaram que a estratégia de enfrentamento 
(Coping) é uma possibilidade de ação para ajustar os desequilíbrios provocados pelo estressor, de modo adaptativo, nem sempre resolutivo.

Dantas (2016, p. 269), mediante Teoria do Apego, demonstrou a importância da formação de vínculos na Equoterapia e implicações decorrentes de seu rompimento em face de mau prognóstico de indivíduos com Amiotrofia Muscular Espinal (AME). Os autores reforçam que os familiares de portadores de AME podem, em muitos casos, já terem experienciado o luto pela perda do que consideravam o filho perfeito. $\mathrm{O}$ autor "propôs-se a busca de alternativas para continuidade do contato entre praticante, equipe técnica e cavalo como cuidado paliativo capaz de evitar sofrimento adicional com o rompimento definitivo do vínculo cultivado como condição para o tratamento". Importante ressaltar que a disponibilidade para o afeto "pode oferecer a sensação de alívio para a solidão existencial e acalanto para o desespero" (FUKUMITSU, 2014, p. 274).

Ademais, Dantas (2016) destacou a relevância de uma intercessão entre a equipe interdisciplinar e a família, de modo que, mesmo sem a montaria, decidam pela manutenção o tratamento equoterápico. Pereira et al. (2018) evidenciaram que que a Equoterapia trouxe benefício para a qualidade de vida da crianças com necessidades especiais que realizam a modalidade, conforme a opinião de $77,8 \%$ dos pais.

Para Elias (2003) o atendimento psicológico conforme premissa da Psicoterapia Breve de apoio, desenvolvido mediante integração de técnicas de relaxamento mental e visualização de imagens mentais com os elementos que descrevem a natureza da espiritualidade, o qual foi oferecido a sete indivíduos (quatro crianças e três adolescentes) com câncer terminal, possibilitou asseverar que esse atendimento ao paciente sem possibilidade de cura ressignificou a dor simbólica da morte (dor psíquica e espiritual para adolescentes; e dor psíquica entre as crianças) e proporcionou qualidade de vida ao processo de morrer e uma morte serena e digna.

Sabe-se que mesmo diante de uma dor intolerável devido à doença, tratar o indivíduo sem possibilidades de cura com compreensão emocional e respeito, em ambiente domiciliar ou hospitalar, com recursos possíveis e paliativos, pode aliviar o sofrimento e proporcionar uma morte digna (FERREIRA; SOUSA, 2013).

Estudo que explorou as respostas de 13 mães enlutadas devido à morte de uma criança por câncer, revelou insights sobre as características de adaptação materna ao luto e a perda, em que as respostas indicaram, ao longo do tempo, que elas enfrentaram situações que variaram em adaptáveis ou complicados, com diferenças importantes no enfretamento do luto (GERRISH; BAILEY, 2020). Afinal, a relação com o infante falecido é parte integrante da vida da mãe enlutada e influencia seu funcionamento (BORTZ; MALKINSON; KRULIK, 2013).

Oishi (2014), a partir de atendimentos psicoterápicos individuais breves de orientação psicanalítica, objetivou compreender a vivência materna durante a elaboração do luto após a perda 
de um filho no período neonatal. A manifestação do luto mediante rituais e psicoterapia facilitou a elaboração de uma "aceitação" da morte e um luto saudável.

Schmidt, Gabarra e Gonçalves (2011), mediante psicoterapia hospitalar breve, constataram que reconfiguração das relações familiares nos diferentes papéis e funções, na perspectiva de maior autonomia após vivenciarem a iminência de morte de ente querido em estado terminal. O processo (ritual) de despedida é uma experiência libertadora, pois permite transformações e resgates das relações familiares, além de possibilitar a elaboração do processo de luto, entre o doente, a família e a equipe de saúde. Portanto, fundamental para fortalecer vínculos mais salutares na perspectiva da qualidade de vida aos familiares, na qualidade de morte para o doente e aos profissionais de saúde aos tornarem-se protagonistas ao proverem recursos saudáveis para o enfrentamento dessa fase desafiadora na vida das famílias, prevenindo sintomas psicológicos futuros entre os que sofrem a perda.

Fukumitsu e Kovács (2016) extraíram 14 unidades de significados mediante o Método Fenomenológico e compreendidas pela abordagem da Gestalt-Terapia. Para os autores, ao enfrentar a morte (decorrente de suicídio), o ente querido/filho pode experienciar o sofrimento com sentimentos de culpa, raiva, sensações de desamparo, abandono, rejeição, solidão, além da fragmentação de tudo o que era conhecido. Portanto, ao catalogar os sentidos, é possível intervir adequadamente e prover melhorias gerais para o enfrentamento do luto e da morte.

Michel e Freitas (2021), também fundamentados no Método Empírico-Fenomenológico de investigação em psicologia de Amedeo Giorgi, entrevistaram quatro mães enlutadas, em que a partir dos seus relatos pode-se asseverar que a relação particular estabelecida entre a mãe enlutada e o psicoterapeuta pode determinar as possibilidades de ressignificação da sua relação com seus filhos falecidos, com seus familiares, com a morte e com a própria vida, desde que se sintam acolhidas, compreendidas e adquiram confiança para se expressarem livremente.

Silva e Nardi (2011a), buscando apresentar um caso de tratamento de luto devido à perda gestacional, fundamentado no Protocolo Cognitivista Comportamental e executado e 12 sessões, a paciente apresentou minimização da sintomatologia depressiva, ansiosa e nos quadros de desesperança, além de resultados positivos no Questionário de Saúde Geral, com redução no desejo de morte, nos desajustes psicossomáticos e benesses na qualidade do sono, corroborando com melhorias gerais nos níveis de qualidade de vida e facilitação da reintegração social.

Em outro estudo das autoras citadas (SILVA; NARDI, 2011b), agora com o propósito de discorrer sobre o processo de luto devido à morte súbita de cônjuge, mas mantendo o uso do protocolo de atendimento cognitivista comportamental, evidenciaram melhorias nos quadros de depressão, ansiedade e desesperança, assim como na pesquisa anterior com mãe enlutada. Ademais, quanto ao estresse, migrou-se da fase de exaustão à de resistência, além de melhorias significativas em relação ao estresse psíquico, na desconfiança em relação ao próprio desempenho, nos distúrbios do sono e psicossomáticos, bem como no desejo de morrer. Para 
Basso e Wainer (2011) a Terapia Cognitivo-Comportamental, prover uma importante contribuição no que se refere ao manejo do luto.

No estudo de Tsutsumi et al. (2017) abordou-se, no processo terapêutico (atendimento psicoterapêutico baseado na Terapia Analítico-Comportamental Infantil), um menino de seis anos que perdeu o pai suicida e o qual foi conduzido por sua mãe para a clínica escola, que demonstrava angústia em face das perguntas que o menino fazia sobre a forma de falecimento do pai. O objetivo terapêutico foi ampliar o saber da criança sobre a figura paterna e foram realizadas também intervenções com a mãe. Ao todo, 25 sessões foram realizadas (12 com o menino e 13 com a mãe) e foram evidenciadas melhorias no comportamento da criança após intervenções. Os autores reforçam que os resultados positivos foram alcançados mediante articulação entre mãe, psicoterapeuta e a equipe de supervisão da clínica onde foram realizados os trabalhos.

Por conseguinte, Strauch (2017) usou o Psicodrama para articular e redefinir o luto em modelos individuais e grupais. Ao lidar com a morte no contexto do psicodrama, o indivíduo tem potencial para reexaminar a perda que surge das realizações simbólicas trazidas pela realidade complementar e a salvação de vínculos saudáveis, espontaneidade e autoconhecimento. Dentre as intervenções propostas para vivências grupais abertas, as técnicas de Psicodrama são ferramentas essenciais para o fortalecimento dos papéis interpessoais e sociais do sujeito.

Enfim, pode-se assegurar conforme Cardoso et al. (2013), que a adoção de estratégias que visem ajudar a superar o luto e a vivência com a morte a construção de vínculo com o paciente e família para garantir a humanização e a integralidade do cuidado, apoiando e respeitando o processo de luto com base na empatia, utilizando crenças espirituais e o compartilhamento de experiências com seus pares como estratégias de enfrentamento. Rodríguez et al. (2013) concordam com os autores e acrescentam a importância do não julgamento durante a realização do cuidado.

Crenças e práticas espirituais, muitas vezes, podem auxiliar tanto o profissional quanto o paciente, que juntos reconstroem o significado da vida quando enfrentam a dor de uma perda. Estudo aponta que o enfrentamento espiritual ou religioso durante o luto é uma estratégia utilizada para confrontar o momento vivenciado, proporcionando força interior, conforto e consolo aos familiares que vem a enfrentar essa situação delicada (HAWTHORNE; YOUNGBLUT; BROOTEN, 2016).

Ademais, parece insubstituível o trabalho interdisciplinar e colaborativo entre o psicoterapeuta e os demais profissionais da saúde (SCHMIDT; GABARRA; GONÇALVES, 2011; FERREIRA; SOUSA, 2013; FUKUMITSU, 2014; DANTAS, 2016; TSUTSUMI et al., 2017). Portanto, para a prática, devem-se adotar programas de treinamento para profissionais da saúde para que possam intervir adequadamente no processo de luto e de morte, especialmente diante da perda materna (BORTZ; MALKINSON; KRULIK, 2013). Devem buscar um maior preparo, contemplando os aspectos técnicos, éticos e espirituais (LACERDA et al., 2016). 
Incluir os familiares no cuidado é essencial para a integralidade do cuidado e valorização da necessidade de alívio do sofrimento psicológico e espiritual presente no processo de morte e morrer. Assim, cabe aos profissionais de saúde priorizar as preocupações e anseios da família em luto durante a assistência a fim de prepará-los para aceitar a perda e lidar com a dor, dessa forma constituindo como uma ferramenta de efetivar o processo de educação para a morte, em que debater sobre a morte pode facilitar a aprendizagem, favorecer o tratamento respeitoso com outras pessoas e a auxiliar na tomada de decisão eficaz (CHAN; LEE; CHAN, 2014). Apoiar a comunicação da experiência vivida e observações consideradas por quem está em processo de luto, como em estudo com mães enlutadas ao longo dos dois primeiros anos após a morte de uma criança pode proporcionar um consolo e alivio efetivo (MEISENHELDER, 2021).

\section{CONSIDERAÇÕES FINAIS}

Os profissionais da área de Psicologia têm buscado inúmeras abordagens psicológicas, teorias, técnicas, instrumentos e/ou intervenções para auxiliar os enlutados. Foi possível constatar que entre as abordagens psicológicas em evidência nesta revisão destacaram-se a Psicanálise de Sigmund Freud e a Terapia Cognitivo-Comportamental de Aaron Beck. A teoria base majoritária foi o Protocolo Cognitivo-Comportamental e a Psicoterapia também se destacou, mas com especificidades, uma que variou entre Psicoterapia Breve, Psicoterapia Hospitalar Breve e Psicoterapia Individual. Importante mencionar que muitos estudos adotaram mais de uma teoria para prover as intervenções ante ao luto/morrer e que todas mostraram resultados bastante eficazes, com repercussões significativas em vários desarranjos, tais como quadros de depressão, ansiedade, distúrbios do sono, vontade de morrer, desajustes psicossomáticos e outros.

Ao considerar às técnicas, o protocolo de atendimento para luto e as estratégias lúdicas foram as mais citadas e quanto os instrumentos e/ou intervenções, as entrevistas apresentaram maior aplicabilidade.

Os resultados deste estudo podem auxiliar na compreensão das ações e interações que envolvem o cuidado ao paciente e família em processo de morte e morrer e suscitar discussões acerca do tema. Apresenta subsídios importantes para a atuação de psicólogos, bem como para outros profissionais da área de saúde, a qual exige ações complexas com a demanda de formação e educação permanente, como abordagem holística e integral, escuta qualificada, empatia e atuação interdisciplinar. 


\section{REFERÊNCIAS}

AQUINO, T. A. A; VASCONCELOS, S. X. P.; BRAGA, D. O. L. Correlatos existenciais da aceitabilidade da morte: Um estudo à luz do sentido na vida. Psicol. argum, p. 161-174, 2014.

BASSO, L. A; WAINER, R. Luto e perdas repentinas: contribuições da Terapia CognitivoComportamental. Revista Brasileira de Terapias Cognitivas, v. 7, n. 1, p. 35-43, 2011.

BORTZ, A. P.; MALKINSON, R.; KRULIK, T. Bereaved Jewish Mothers of Children Who Died of Cancer. Cancer Nursing, v. 36, n. 5, E1-E8, 2013.

CARDOSO, D. H. et al. Hospice care in a hospital setting: the experience of a multidisciplinary team. Texto contexto-enferm., v. 22, n. 4, p. 1134-41, 2013.

CHAN, H. Y. L.; LEE, L. H.; CHAN, C. W. H. The perceptions and experiences of nurses and bereaved families towards bereavement care in an oncology unit. Supportive care in cancer, $v$. 21, n. 6, p. 1551-1556, 2013.

CORRÊA, D. A. Do luto ao sentido: aportes da logoterapia no espaço psicoterapêutico. Psicologia: teoria e prática, v. 14, n. 3, p. 180-188, 2012.

COSTA, D. H.; NJAINE, K.; SOUZA, E. R. Apoio institucional a famílias de vítimas de homicídio: análise das concepções de profissionais da saúde e assistência social. Trabalho, Educação e Saúde, v. 18, n. 3, e00282114, 2020.

COSTA, M.; MOTA, C. P.; MILHEIRO, C. Angústia de uma perda-caso Maria: uma abordagem terapêutica. Psicologia Clínica, v. 25, p. 197-213, 2013.

CRAVINHO, C. R. M.; CUNHA, A. C. B. Enfrentamento da morte fetal pela enfermagem na abordagem disposicional e na Teoria Motivacional do Coping. Estudos de Psicologia (Campinas), v. 32, p. 307-317, 2015.

DANTAS, M. M. M. Amiotrofia Muscular Espinal, terminalidade e desligamento do programa de equoterapia: reflexão sobre o rompimento de vínculos. Psicologia Argumento, v. 34, n. 86, p. 256-272, 2016.

ELIAS, A. C. A. Re-significação da dor simbólica da morte: relaxamento mental, imagens mentais e espiritualidade. Psicologia: Ciência e Profissão, v. 23, n. 1, p. 92-97, 2003.

FARIA, S. S.; FIGUEREIDO, J. S. Aspectos emocionais do luto e da morte em profissionais da equipe de saúde no contexto hospitalar. Psicol. hosp. (São Paulo), v. 15, n. 1, p. 44-66, 2017.

FERREIRA, E. B.; SOUSA, M. N. A. de. Eutanásia: percepção de graduandos em enfermagem. Ciência \& Desenvolvimento-Revista Eletrônica da FAINOR, v. 6, n. 2, p. 201$228,2013$.

FERREIRA, J. M. G.; NASCIMENTO, J. L.; SÁ, F. C. Profissionais de saúde: um ponto de vista sobre a morte e a distanásia. Revista Brasileira de Educação Médica, v. 42, p. 87-96, 2018.

FRANKL, V. E. Em busca de sentido: um psicólogo no campo de concentração. São Leopoldo: Editora Sinodal, 2013. 
FUKUMITSU, K. O. O psicoterapeuta diante do comportamento suicida. Psicologia USP, v. 25, p. 270-275, 2014.

FUKUMITSU, K. O.; KOVÁCS, M. J. Especificidades sobre processo de luto frente ao suicídio. Psico, v. 47, n. 1, p. 3-12, 2016.

GERRISH, N. J.; BAILEY, S. Maternal grief: a qualitative investigation of mothers' responses to the death of a child from cancer. OMEGA-Journal of Death and Dying, v. 81, n. 2, p. 197$241,2020$.

HAWTHORNE, D. M.; YOUNGBLUT, J. M.; BROOTEN, D. Parent spirituality, grief, and mental health at 1 and 3 months after their infant's/child's death in an intensive care unit. Journal of pediatric nursing, v. 31, n. 1, p. 73-80, 2016.

HERMONT, A. P. et al. Revisões integrativas em Odontologia: conceitos, planejamento e execução. Arquivos em Odontologia, v. 57, p. 3-7, 2021.

KOVÁCS, M. J. Educação para a morte. Psicologia: ciência e profissão, v. 25, p. 484-497, 2005.

LACERDA, C. A. et al. O lidar com a morte em unidade de terapia intensiva: dificuldades relatadas por enfermeiros. Revista Ciência \& Desenvolvimento, v. 9, p.173-184, 2016.

LIMA, M. J. V.; ANDRADE, N. M. A atuação do profissional de saúde residente em contato com a morte e o morrer. Saúde e Sociedade, v. 26, p. 958-972, 2017.

MEISENHELDER, J. B. Maternal grief: analysis and therapeutic recommendations. BMJ Supportive \& Palliative Care, v. 11, n. 1, p. 101-106, 2021.

MENDES, G. C. et al. O Impacto da Morte em Profissionais da Saúde em Contexto Hospitalar. Revista PsicoFAE: Pluralidades em Saúde Mental, v. 9, n. 2, p. 58-66, 2020.

MICHEL, L. H. F.; FREITAS, J. L. A clínica do luto e seus critérios diagnósticos: possíveis contribuições de Tatossian. Psicologia USP, v. 30, p. 1-9, 2019.

MICHEL, L. H. F.; FREITAS, J. L. Psicoterapia e luto: a vivência de mães enlutadas. Psicologia: Ciência e Profissão, v. 41, 2021.

MOCELIN, D. et al. Processos psicológicos dos profissionais da saúde perante a morte de um paciente. VITTALLE-Revista de Ciências da Saúde, v. 26, n. 1, p. 11-20, 2014.

MOREIRA, N.; HOLANDA, A. Logoterapia e o sentido do sofrimento: convergências nas dimensões espiritual e religiosa. Psico-USF, v. 15, p. 345-356, 2010.

OISHI, K. L. O jardim de Julia: a vivência de uma mãe durante o luto. Psicologia: teoria e pesquisa, v. 30, p. 5-11, 2014.

PEREIRA, L. T. V. et al. Expectativas e sentimentos de familiares cuidadores de crianças com necessidades especiais que realizam equoterapia. Revista de Ciências Médicas e Biológicas, v.18, n. 2, p. 217-223, 2018. 
RODRÍGUEZ, R. G. et al. Develando el significado del proceso de duelo em enfermeras(os) pediátricas(os) que se enfrentan a la muerte de un paciente a causa del cáncer. Aquichan, v. 13, n. 1, p. 81-91, 2013.

SALUM, M. E. G. et al. Processo de morte e morrer: desafios no cuidado de enfermagem ao paciente e família. Rev Rene, v. 18, n. 4, p. 528-535, 2017.

SCHMIDT, B.; GABARRA, L. M.; GONÇALVES, J. R. Intervenção psicológica em terminalidade e morte: relato de experiência. Paidéia (Ribeirão Preto), v. 21, p. 423-430, 2011.

SILVA, A. C. O.; NARDI, A. E. Terapia cognitivista-comportamental para perda gestacional: resultados da utilização de um protocolo terapêutico para luto. Archives of Clinical Psychiatry (São Paulo), v. 38, p. 122-124, 2011a.

SILVA, A. C. O.; NARDI, A. E. Terapia cognitivo-comportamental para luto pela morte súbita de cônjuge. Archives of Clinical Psychiatry (São Paulo), v. 38, p. 213-215, 2011 b.

SILVA, S.; CARNEIRO, M. I. P.; ZANDONADI, A. C. O luto patológico e a atuação do psicólogo sob o enfoque da psicoterapia dinâmica breve. Revista Farol, v. 3, n. 3, p. 142-157, 2017.

SOUSA, M. N. A. de. Revisão integrativa da literatura: esclarecendo o método. In: SOUSA, M. N. A. de; SANTOS, E. V. L. Medicina e pesquisa: um elo possível. 1. ed. Curitiba: Editora Prismas, 2016, v.1, p. 345-358.

STRAUCH, V. R. F. Ressignificação da morte na abordagem psicodramática: perdas e ganhos no luto. Rev. bras. psicodrama, São Paulo, v. 25, n. 1, p. 59-67, 2017.

SUÁREZ, L. A. B.; CALDAS, M. T.; SOUSA, M. N. A. Elos da Psicologia: logoterapia e tanatologia. SOUSA, M. N. A. et al. (Orgs). 1. ed. Curitiba: Appris, 2018. p. Saúde e bioética em foco: coletânea de artigos multitemáticos. SOUSA, M. N. A. et al. 1 ed. Curitiba: Appris, 2018. p. 375-384.

SUÁREZ, L. A. B.; SOUSA, M. N. A.; CALDAS, M. T. Entre flores e sepultura: a maternidade e o processo de perda de um filho. Revista Brasileira de Educação e Saúde, v. 10, p. 23-30, 2020.

TSUTSUMI, M. M. A. et al. Terapia Comportamental Infantil na relação mãe e filho ante o luto materno-um relato de caso. Revista Brasileira de Psicoterapia, v. 19, n. 3, p. 53-62, 2017.

Recebido em: 15/01/2022

Aprovado em: 05/02/2022

Publicado em: 10/02/2022 